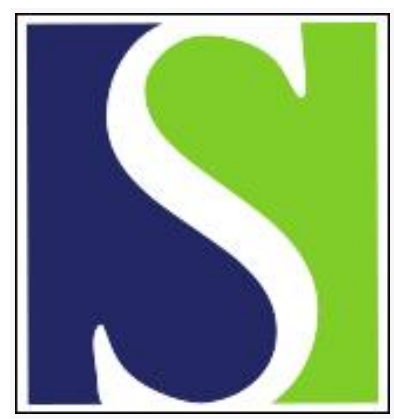

Scand J Work Environ Health 2011;37(5):446-449

https://doi.org/10.5271/sjweh.3155

Published online: 01 Mar 2011, Issue date: Sep 2011

Does outdoor work during the winter season protect against depression and mood difficulties?

by Hahn IH, Grynderup MB, Dalsgaard SB, Thomsen JF, Hansen ÅM, Kærgaard A, Kærlev L, Mors O, Rugulies R, Mikkelsen S, Bonde JP, Kolstad HA

Affiliation: Danish Ramazzini Centre, Department of Occupational Medicine, Århus University Hospital, DK-8000 Århus C, Denmark. henkol@rm.dk

Refers to the following texts of the Journal: 2007;33(3):198-203 2005;31(6):438-449

Key terms: chronobiology disorder; depression; depressive disorder; epidemiology; light; mood difficulty; mood disorder; occupational exposure; outdoor work; seasonal affective disorder

This article in PubMed: www.ncbi.nlm.nih.gov/pubmed/21359494 


\title{
Does outdoor work during the winter season protect against depression and mood difficulties?
}

\author{
by Ina H Hahn, BSc, ${ }^{1}$ Matias B Grynderup, MA, ${ }^{1}$ Sofie B Dalsgaard, BSc, ${ }^{1}$ Jane F Thomsen, MD, ${ }^{2}$ Åse \\ Marie Hansen, PhD, ${ }^{3}$ Anette Kærgaard, MD, ${ }^{4}$ Linda Kærlev, MD, ${ }^{1}$ Ole Mors, MD, ${ }^{5}$ Reiner Rugulies, PhD, ${ }^{3}$ \\ Sigurd Mikkelsen, MD, ${ }^{2}$ Jens Peter Bonde, MD, ${ }^{2}$ Henrik A Kolstad, MD ${ }^{1}$
}

\begin{abstract}
Hahn IH, Grynderup MB, Dalsgaard SB, Thomsen JF, Hansen ÅM, Kærgaard A, Kærlev L, Mors 0, Rugulies R, Mikkelsen S, Bonde JP, Kolstad HA. Does outdoor work during the winter season protect against depression and mood difficulties? Scand J Work Environ Health 2011;37(5):446-449. doi:10.5271/sjweh.3155
\end{abstract}

\begin{abstract}
Objective At temperate latitudes, $1-5 \%$ of the population suffer from winter depression; during winter, mood difficulties tend to increase but may be alleviated by bright light therapy. Unlike indoor workers, outdoor workers are exposed to therapeutic levels of sunlight during winter. We hypothesized that outdoor work may protect against mood difficulties and depression.
\end{abstract}

Method We studied this hypothesis among 2910 civil servants from Århus, Denmark, who participated in a survey in January-February 2009. Mental symptoms $(\mathrm{N}=422)$ defined a common case category that we broke down into two parts: depression $(\mathrm{N}=66)$ and mood difficulties but no depression $(\mathrm{N}=356)$. A total of 222 controls were also sampled from the study population. All 644 participants reported the extent of outdoor work.

Results The confounder-adjusted odds ratio (OR) of mood difficulties showed a decreasing trend by increasing hours of outdoor work of borderline statistical significance. The OR was 0.63 [95\% confidence interval $(95 \%$ CI) $0.34-1.18$ )] for those working outdoors for $>2$ hours a day. No such effect was suggested for depression.

Conclusion Our study is limited by its cross-sectional design and low statistical power but nevertheless suggests that outdoor work during winter may protect against mood difficulties. If this finding holds true, it may have significant impact on workers' health as well as public health in general. Therefore, further studies are recommended.

Key terms chronobiology disorder; depressive disorder; epidemiology; light; mood disorder; occupational exposure; seasonal affective disorder.

At temperate latitudes, $1-5 \%$ of the population suffer from winter depression (1-3). During winter, mood difficulties tend to increase and more anti-depressive treatments are initiated (4). Bright-light therapy with an illuminance $>2500$ lux for 2 hours a day has a well-documented effect on seasonal and non-seasonal depression and depressive symptoms $(5,6)$. In Denmark (latitude $55-57^{\circ} \mathrm{N}$ ) or other areas at temperate latitudes, indoor workers constitute $80-90 \%$ of the workforce (7). During winter, they are not exposed to sunlight during working days due to the short-day lengths but only to artificial lighting about 100 lux (8). This is contrary to outdoor workers, who are exposed to significantly higher levels of light that may reach the background level of sunlight of about 10000 lux for 2 hours about noon during the darkest winter months (9). We therefore hypothesized that outdoor work during winter may protect against depression and mood difficulties.

\section{Methods}

\section{Study population}

The study sample consisted of civil servants from the City of Århus, Denmark, who were recruited for a longitudinal study of occupational risk factors for mental health (10).

\footnotetext{
${ }^{1}$ Danish Ramazzini Centre, Department of Occupational Medicine, Aarhus University Hospital, Århus, Denmark.

2 Department of Occupational and Environmental Medicine, Copenhagen University Hospital Bispebjerg, Copenhagen, Denmark.

3 National Research Centre for the Working Environment, Copenhagen, Denmark.

${ }^{4}$ Department of Occupational Medicine, Regional Hospital Herning, Herning, Denmark.

${ }^{5}$ Centre for Psychiatric Research, Århus University Hospital, Risskov, Denmark.
}

Correspondence to: Dr Henrik A Kolstad, Danish Ramazzini Centre, Department of Occupational Medicine, Århus University Hospital, Norrebrogade 42, DK-8000 Århus C, Denmark. [henkol@rm.dk]. 
In 2007, 10036 workers were identified from personnel records and $4489(45 \%)$ returned a postal questionnaire about working conditions and mental health. During the winter (January-February) of 2009, 2910 (65\%) of those responding in 2007 answered a second questionnaire. The 317 participants $(6 \%)$ who responded after this period were not included in this analysis. We invited 601 of those who reported mental symptoms (high levels of depressive, stress, or burnout symptoms) to participate in a clinical examination that included a psychiatric diagnostic interview [schedules for clinical assessment in neuropsychiatry (SCAN)] that took place during the spring (March-June) 2009. A total of 422 participated (70.2\%), 66 were diagnosed with DSM-IV (Diagnostic and Statistical Manual of Mental Disorders, $4^{\text {th }}$ edition) depression present during the two winter months $(15.6 \%)$ and 3 $(0.7 \%)$ were diagnosed with DSM-IV depression with a later onset. Mental symptoms $(\mathrm{N}=422)$ defined a common case category that we broke down into depression $(\mathrm{N}=66)$ and mood difficulties but no depression $(\mathrm{N}=356)$ present during winter. For the control group, we invited 356 respondents, of which 222 (62.4\%) participated in the clinical examination irrespective of their mental health status and they were not SCAN interviewed. The total study population therefore included 644 persons.

The postal questionnaire enquired about depressive symptoms according to the Common Mental Disorder Questionnaire (6 questions) (11), stress symptoms according to the Perceived Stress Scale (4 questions) (12), and symptoms of burnout based on the Copenhagen Burnout Inventory (6 questions) (13). All were answered on a 5-point scale ranging from 1 ("not at all"/"never") to 5 "extremely"/"always"). Each of the 6 questions on depressive symptoms was assigned a value of 1 if the point score was $\geq 3$, otherwise it was given a value of null. Participants were classified with depressive symptoms if they had a sum score $>2$. High stress and burnout scores were defined as mean scores $\geq 2.5$. Respondents with high scores on two of the three dimensions were classified as having mental symptoms and were invited to the SCAN examination. In addition, the postal questionnaire enquired about potential confounding factors.

We used the following sections of part I of SCAN, version 2.1, to evaluate a possible diagnosis of a major depressive episode according to DSM-IV: depressive mood, concentration, energy and bodily functions (sections 6,7 , and 8 , respectively), expansive mood (section 10 ), and the screen for psychotic symptoms (section 14). The interviews focused on the previous three months and enquired about the duration of symptoms beyond this interval. From the latter information, we estimated a date of onset. The interviews were obtained by computer aided, semi-structured, diagnostic interviewing (14) and were undertaken by ten undergraduate students in medicine or psychology. Inter-rater reliability on item level was found to be satisfactory $(\kappa=0.71)$.

During the clinical examination, the 644 participants were asked about their weekly (five working days) hours of outdoor work during the 2009 winter season. The scientific ethics committee of Arrhus County approved the study and participants gave written, informed consent.

\section{Statistical analysis}

Using multivariate logistic regression, we analyzed odds ratios (OR) with $95 \%$ confidence intervals $(95 \% \mathrm{CI})$ according to the duration of outdoor work. All models also included dummy variables for gender, education (3 levels), previous depressive disorder, family history of depression, age (4 levels), alcohol consumption $(</ \geq 14$ grams/week), physical job (1 indicator variable for cleaners, craftsmen, unskilled workers, gardeners, fire fighters, nurses, and nursing associates), and income as well as psychosocial work factors ( 2 indicator variables for decision latitude and psychological demands). These covariates were decided upon a priori and were included in all models. We repeated all analyses based on continuous exposure variables as a sensitivity check and for the assessment of trends. All analyses were conducted with SAS, version 9.1.3 statistical software (SAS Institute Inc, Cary, NC, USA).

\section{Results}

In this population of civil servants, the distribution of outdoor work during winter was highly skewed. A total of 208 participants $(32 \%)$ had any outdoor work and $8 \%$ worked for $>2$ hours a day during winter. Within the latter category of outdoor workers, the most prevalent professions were unskilled workers $(17 \%)$, social workers $(17 \%)$, managers $(15 \%)$, and preschool teachers $(13 \%)$. Outdoor work was most prevalent among unskilled workers $(70 \%)$, gardeners $(66 \%)$, and fire fighters $(50 \%)$ and rare among office clerks (2\%), cooks, kitchen helpers, psychologists, administration professionals, medical secretaries and information technology professionals $(0 \%)$.

The adjusted OR of mental symptoms during winter showed an inverse trend by daily hours of outdoor winter work of borderline statistical significance (OR $0.93,95 \%$ CI $0.84-1.02$, table 1). Among those working outdoor for $>2$ hours a day, the OR was $0.69(95 \% \mathrm{CI}$ 0.39-1.21) when compared with those working outdoor for less time. Additional hours of outdoor work did not appear to affect the risk further. A similar trend was seen for mood difficulties (OR 0.93, 95\% CI 0.84-1.02) and the OR for $>2$ hours of daily outdoor work was 0.62 (95\% CI 0.33-1.17). For depression the association was weak (OR 0.96, 95\% CI 0.80-1.14). 


\section{Discussion}

This study suggests that outdoor work during the winter season has a gainful effect on mood but not on depression. Previously, an increased occurrence of seasonal affective disorder (SAD) and subsyndromal-SAD has been suggested in indoor professions (15), but seasonal changes in mood were not affected by an indoor job (16). These studies did not include information on the extent of outdoor work but were based on expert classifications of jobs into indoor and outdoor jobs. Outdoor walking has been shown to have a therapeutic effect on patients diagnosed with SAD comparable to that seen for light therapy (17), and occupational exposure to daylight has been associated with less symptoms of burnout (18). Contradictory findings are made for the association between objective measures of winter illumination and a diagnosis of SAD, SAD scores, or low winter mood in the general population $(19,20)$. Our definition of depression did not include the atypical vegetative symptoms of SAD but focused on depression present during winter and thus is not directly comparable with these previous studies.

The strengths of this study are the well-described study population and access to clinical data obtained according to a common protocol that separated cases diagnosed with depression from cases with sub-clinical mood difficulties. We were furthermore able to adjust for a number of well-documented risk factors for depressive disorders as well as adverse psychosocial working conditions.
Outdoor work is more prevalent among lower-educated participants; low social status is a risk factor for depressive disorders, and our results may thus have been biased towards no effect even if we had adjusted for income and educational level. However, confounder adjustment does not change the crude estimates very much and this indicates that confounding is not a major problem.

The psychiatric interviews were conducted during spring when ambient light levels are significantly higher and days longer than during winter. Therefore symptoms may have been alleviated primarily among the indoor workers and participants who fulfilled the diagnostic criteria for depression during winter may have been overseen, even if the interviews focused on the previous three months. This may have contributed to the "no effect" suggested for depression if an effect of light is acute and transient but cannot explain the suggested effect seen for all cases of mental symptoms during winter.

The cross-sectional design was another weakness and our findings could be due to reverse causality if workers with mental problems prefer indoor work. The low prevalence of outdoor work and thus low statistical power is also a limitation. We do not know if the information on outdoor work provided by the participants is biased on mood status, but one may speculate that those with low mood under-report outdoor work and this would also tend to bias our results towards no effect.

Several causal mechanisms may be involved. Outdoor work may exert the effect through visible light that normalizes circadian rhythm or have a gainful effect on

Table 1. Outdoor work during winter and odds ratios (OR) of depression, mood difficulties and mental symptoms during winter among 644 public servants, Århus, Denmark 2009. [95\% Cl=95\% confidence interval.]

\begin{tabular}{|c|c|c|c|c|c|c|}
\hline Duration of wintertime outdoor work & $\begin{array}{l}\text { Controls } \\
(\mathrm{N}=222)\end{array}$ & Cases & Crude OR & $95 \% \mathrm{Cl}$ & $\begin{array}{c}\text { Adjusted } \\
\mathrm{OR}^{\mathrm{a}}\end{array}$ & $95 \% \mathrm{Cl}$ \\
\hline \multicolumn{7}{|l|}{ Depression } \\
\hline 0 hours/week & 152 & 42 & 1.00 & .. & 1.00 & . \\
\hline$>0$ hours/day & 70 & 24 & 1.24 & $0.70-2.21$ & 1.30 & $0.63-2.68$ \\
\hline$>2$ hours/day & 23 & 6 & 0.86 & $0.34-2.22$ & 0.65 & $0.20-2.12$ \\
\hline$>4$ hours/day & 17 & 6 & 1.21 & $0.45-3.20$ & 0.84 & $0.25-2.87$ \\
\hline$>6$ hours/day & 13 & 4 & 1.04 & $0.33-3.30$ & 0.83 & $0.20-3.51$ \\
\hline Continuous measure (hours/day) & 222 & 66 & 1.00 & $0.87-1.15$ & 0.96 & $0.80-1.14$ \\
\hline \multicolumn{7}{|l|}{ Mood difficulties } \\
\hline 0 hours/week & 152 & 242 & 1.00 & .. & 1.00 & . \\
\hline$>0$ hours/day & 70 & 114 & 1.02 & $0.71-1.47$ & 1.03 & $0.70-1.53$ \\
\hline$>2$ hours/day & 23 & 25 & 0.65 & $0.36-1.18$ & 0.62 & $0.33-1.17$ \\
\hline$>4$ hours/day & 17 & 18 & 0.64 & $0.32-1.27$ & 0.63 & $0.30-1.32$ \\
\hline$>6$ hours/day & 13 & 12 & 0.56 & $0.25-1.25$ & 0.52 & $0.22-1.22$ \\
\hline Continuous measure (hours/day) & 222 & 356 & 0.93 & $0.85-1.02$ & 0.93 & $0.84-1.02$ \\
\hline \multicolumn{7}{|l|}{ Mental symptoms ${ }^{b}$} \\
\hline 0 hours/week & 152 & 284 & 1.00 & .. & 1.00 & .. \\
\hline$>0$ hours/day & 70 & 138 & 1.06 & $0.74-1.50$ & 1.05 & $0.72-1.55$ \\
\hline$>2$ hours/day & 23 & 31 & 0.69 & $0.39-1.21$ & 0.63 & $0.34-1.18$ \\
\hline$>4$ hours/day & 17 & 24 & 0.72 & $0.38-1.38$ & 0.68 & $0.34-1.38$ \\
\hline$>6$ hours/day & 13 & 16 & 0.63 & $0.30-1.34$ & 0.56 & $0.25-1.28$ \\
\hline Continuous measure (hours/day) & 222 & 422 & 0.94 & $0.86-1.03$ & 0.93 & $0.84-1.02$ \\
\hline
\end{tabular}

a Adjusted for gender, age, educational level, income, a family history of depression, previous depression, physical work, alcohol consumption, psychological demands and decision latitude.

${ }^{\mathrm{b}}$ Either depression or mood difficulties. 
neurotransmitters (21). Exposure to ultraviolet (UV) radiation and increased vitamin $\mathrm{D}$ levels is not a likely explanation because UV-B levels are negligible during winter at $55-57^{\circ} \mathrm{N}$. Physically demanding work may, on the other hand, be relevant even if we included physical job in our models because we have no information on the level of physical activity. Objective measures may be obtained by portable devices for these exposures.

A high proportion of the workforce at temperate latitudes has indoor work, and mental problems are prevalent in the working population. Thus, if our results hold true, the findings may have significant therapeutic and work design consequences and may also be relevant for public health in general. Therefore, further studies are recommended. They should include a high proportion of outdoor workers, relevant information on known risk factors for depressive disorders and mood difficulties and clinical data obtained during and outside the winter season. Exposure assessment should include individual portable devices that record illumination and activity and a job exposure matrix feasible for large scale epidemiological studies.

\section{Acknowledgments}

This work was supported by a grant from the Danish Work Environment Research Fund (5-2005-09).

\section{References}

1. Magnusson A. An overview of epidemiological studies on seasonal affective disorder. Acta Psychiatr Scand. 2000;101:17684. doi:10.1034/j.1600-0447.2000.101003176.x.

2. Magnusson A, Partonen T. The diagnosis, symptomatology, and epidemiology of seasonal affective disorder. CNS Spectr. 2005;10:625-34.

3. Lewy AJ, Emens JS, Songer JB, Sims N, Laurie AL, Fiala SC et al. Winter Depression: Integrating mood, circadian rhythms, and the sleep/wake and light/dark cycles into a bio-psychosocial-environmental model. Sleep Med Clin. 2009;4:285-99. doi:10.1016/j.jsmc.2009.02.003.

4. Gardarsdottir H, Egberts TC, van DL, Heerdink ER. Seasonal patterns of initiating antidepressant therapy in general practice in the Netherlands during 2002-2007. J Affect Disord. 2010;122:208-12. doi:10.1016/j.jad.2009.06.033.

5. Tuunainen A, Kripke DF, Endo T. Light therapy for non-seasonal depression. Cochrane Database Syst Rev. 2004:CD004050.

6. Partonen T, Lonnqvist J. Bright light improves vitality and alleviates distress in healthy people. J Affect Disord. 2000;57:55-61. doi:10.1016/S0165-0327(99)00063-4.

7. Schweizer C, Edwards RD, Bayer-Oglesby L, Gauderman WJ,
Ilacqua V, Jantunen MJ et al. Indoor time-microenvironmentactivity patterns in seven regions of Europe. J Expo Sci Environ Epidemiol. 2007;17:170-81. doi:10.1038/sj.jes.7500490.

8. Dumont M, Beaulieu C. Light exposure in the natural environment: relevance to mood and sleep disorders. Sleep Med. 2007;8:557-65. doi:10.1016/j.sleep.2006.11.008.

9. Satel-Light. The European Database for Daylight and Solar Radiation. 2011. http://www.satellight.com/core.htm.

10. Kolstad HA, Hansen ÅM, Kaergaard A, Thomsen JF, Kaerlev L, Mikkelsen S et al. Job strain and the risk of depression: Is reporting biased? Am J Epidemiol. 2011 Jan 1;173(1):94-102.

11. Christensen KS, Fink P, Toft T, Frostholm L, Ornbol E, Olesen F. A brief case-finding questionnaire for common mental disorders: the CMDQ. Fam Pract 2005;22:448-57. doi:10.1093/fampra/cmi025.

12. Cohen S, Kamarck T, Mermelstein R. A global measure of perceived stress. J Health Soc Behav 1983;24:385-96. doi: $10.2307 / 2136404$.

13. Kristensen TS, Hannerz H, Hogh A, Borg V. The Copenhagen Psychosocial Questionnaire--a tool for the assessment and improvement of the psychosocial work environment. Scand J Work Environ Health 2005;31:438-49.

14. Celik C. Computer assisted personal interview application for the Schedules for Clinical Assessment in Neuropsychiatry Version 2.1 and diagnostic algorithms for WHO ICD 10 chapter V DCR and for Diagnostic and Statistical Manual for Mental Disorders, version IV, Release 1, Ed. 1.0.4.6. Geneva: World Health Organization; 2005.

15. Magnusson A, Stefansson JG. Prevalence of seasonal affective disorder in Iceland. Arch Gen Psychiatry 1993;50:941-6.

16. Pajunen P, Lonnqvist J, Partonen T. Seasonal changes in mood and behavior in relation to work conditions among the general population. Scand J Work Environ Health. 2007;33:198-203.

17. Wirz-Justice A, Graw P, Krauchi K, Sarrafzadeh A, English J, Arendt J et al. 'Natural' light treatment of seasonal affective disorder. J Affect Disord. 1996;37:109-20. doi:10.1016/01650327(95)00081-X.

18. Alimoglu MK, Donmez L. Daylight exposure and the other predictors of burnout among nurses in a University Hospital. Int J Nurs Stud. 2005;42:549-55. doi:10.1016/j. ijnurstu.2004.09.001.

19. Guillemette J, Hebert M, Paquet J, Dumont M. Natural bright light exposure in the summer and winter in subjects with and without complaints of seasonal mood variations. Biol Psychiatry. 1998;44:622-8. doi:10.1016/S00063223(97)00543-X.

20. Espiritu RC, Kripke DF, ncoli-Israel S, Mowen MA, Mason WJ, Fell RL et al. Low illumination experienced by San Diego adults: association with atypical depressive symptoms. Biol Psychiatry. 1994;35:403-7. doi:10.1016/00063223(94)90007-8.

21. Magnusson A, Boivin D. Seasonal affective disorder: an overview. Chronobiol Int. 2003;20:189-207. doi:10.1081/ CBI-120019310.

Received for publication: 1 October 2010 
